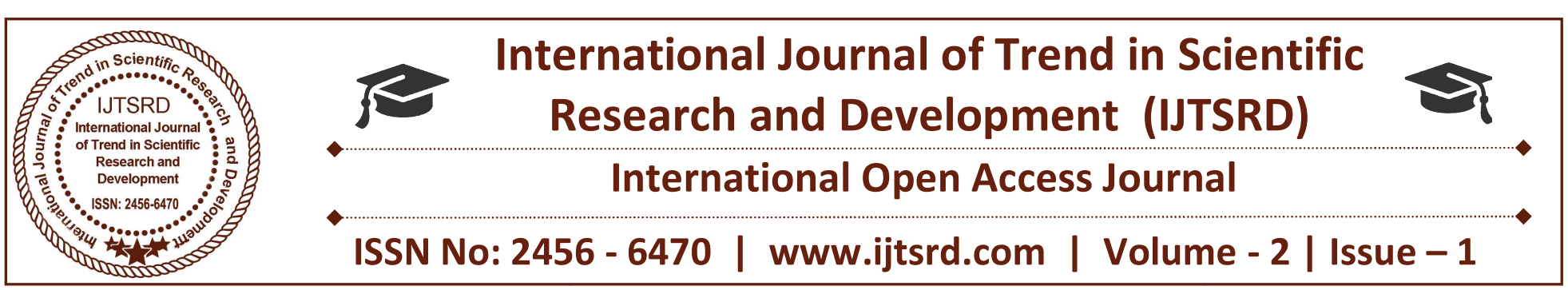

\title{
Assessing the Knowledge towards implementing Practice of Kangaroo Mother Care in Postnatal Mothers
}

\author{
Debajani Nayak \\ Lecturer, Department of Obstetrics and \\ Gynaecological Nursing, SUM Nursing College, \\ Siksha ' $\mathrm{O}$ ' Anusandhan University, \\ Bhubaneswar, 751003, Odisha, India
}

\author{
Sasmita Prusty \\ P.B.Bsc Nursing, 2nd Year, SUM Nursing College, \\ Siksha 'O' Anusandhan University, \\ Bhubaneswar, 751003, Odisha, India
}

\section{ABSTRACT}

Kangaroo Mother Care is a key component of effort to reduce the neonatal mortality, enhance the mother knowledge and practice to improve the child health. The use of simulation for increase the knowledge, practice of the mother for effective KMC has been widespread growth and adaption across maternity institution. The present study aimed to assess the effectiveness of simulation on knowledge and practice among the mother or family member in order to improve the mother knowledge and practice level, also enhance the neonatal health. The objective of the study were to assess the knowledge and practice of the mother about KMC and to find out correlation of knowledge with practice on KMC.An experimental research with one group pre-test post-test design having 50 sample were collected by convenience sampling technique. The study found that; the mean of post-test(6.12) is significantly higher than mean pre-test (4.16) knowledge scores and the mean of post-test (8.22)practice score also higher than mean pre-test (4.32) practice scores. Hence it was concluded that KMC is the best method for both mother and baby. Stimulation based study assist confidence while enhancing the mother ability to knowledge and practice about KMC.

Keyword: Knowledge, Practice, Postnatal mother, Kangaroo Mother Care (KMC)

\section{Introduction:}

Kangaroo mother care (KMC) is the early skin to skin contact between the baby \& the mother. It should be ideally start at birth, but it also helpful at any time.
KMC facilitates mother -infant bonding, improves breastfeeding, make the mother to be more comfortable and relax. Low birth weight (LBW; $<2500 \mathrm{~g}$ ), which is often associated with preterm birth, is a common problem in India. Both are recognized risk factors for neonatal mortality7. Kangaroo Mother Care (KMC) implies placing the new born baby in intimate Skin to Skin contact with the mother's chest \&abdomen coupled with frequent \& preferably exclusive breast feeding KMC is a low cost method for new born care that provides warmth, touch , \& security, improve breast feeding practice \& cardio respiratory stability in infants without negative effects.

KMC improves bonding and attachment between mother and her newborn. It also reduces maternal postpartum depression and psychosis and anxiety of the baby as well as felt secure. Helps for longer duration of breastfeeding so that growth of newborn occurs and weight gain improved. Through frequent breast feeding. It maintains the mother and infant relationship ${ }^{1}$.

Kangaroo Mother Care should begin as soon as possible after birth, be applied as continuous skin-toskin contact to the extent that this is possible and appropriate and continue for as long as appropriate. ${ }^{1}$

Designed to increase the relationship between mother and their preterm infant and to keep the infant physiologically stable, ${ }^{4}$. Its main aim is to provide continuous, and prolonged skin-to-skin contact between mother and infant as much as possible. The 
skin to skin care will improved the outcomes in terms of breastfeeding, weight gain, body temperature, respiration rate, heartrate of the infant, duration of hospital stay, and infant-maternal bonding., ${ }^{3,2} \mathrm{KMC}$ practice had a great advantage for low birth weight infants in India.

KMC improves growth in low birth weight infants and has a significant role in protecting the LBW infant from hypothermia, hypoglycaemia and sepsis. It is definitely feasible, acceptable to mothers and can be continued at home in the Indian set up. ${ }^{5}$ The purpose of this study was to determine the knowledge and implement the practice of KMC upon postnatal mothers and their infants.

\section{Statement of the problems:}

Assess the knowledge and practice of mother regarding kangaroo mother care in a selected hospital of Odisha.

\section{Objective of the study:}

1. To assess the knowledge of the mother about KMC.

2. To impliment the practice of mother about KMC.

\section{Methodology}

Aquassi experimental research approach with Preexperimental one group pre-test post-test design was adopted for this study. 50 postnatal mothers were collected by convenience sampling technique. The tools used for the study were knowledge questionnaire and checklist to assess practice of the mother regarding KMC. The tool was consisted of 3 section. Section A consists demographic characteristics of mother, SectionB consists of 10 question of checklist regarding knowledge aspect and Section $\mathrm{C}$ consists of 10 multiple choice question of practice aspectThe tools were validated by seven experts in the field of the nursing. . The experts were requested to give their suggestion and opinion regarding the relevance, adequacy and appropriateness of the items in the tool. The reliability and feasibility was established by administering the tool to 10 postnatal mother. The obtained data was analysed by using descriptive and inferential statistics in terms of frequency, percentage, and mean, median. ' $t$ ' value and co relation test.

\section{RESULT AND DISCUSSION}

\section{Distribution study samples according to the SocioDemographic variables}

As regards age of the sample, $48 \%$ of samples were in less than 20 years of age, $28 \%$ in between $20-30$ years of age and $24 \%$ in greater than 30 years of age.

Religion of the sample women shows that $50 \%$ of samples were Hindu, $28 \%$ of sample were Christian and $22 \%$ of sample were Muslim.

In education status of the samples $48 \%$ of samples had primary education, $30 \%$ of samples were illiterate and $22 \%$ of samples had high school education.

The maximum $70 \%$ of samples are house wife and $30 \%$ of samples were working mother.

Almost half of the samples that $50 \%$ of samples were stay in hospital from 3-7 days, 30\% of samples were stay in hospital more than 7 days and $20 \%$ of samples were stay in hospital less than 3 days.

For parity of the mothers $42 \%$ of samples were multipara, $36 \%$ of samples were primipara and $22 \%$ of samples were grandmulti para.

\section{Finding related to evaluation ofknowledge regarding KMC}

Table -1: Mean,Median,SD, 't' Value and P Value of pretest and posttest knowledge scores of sample mothers regarding kangaroo mother care.

$\mathrm{N}=50$

\begin{tabular}{|l|l|l|l|l|l|l|}
\hline Group & Mean & Med & SD & df & $\begin{array}{l}\text { 't' } \\
\text { Value }\end{array}$ & $\begin{array}{l}\text { P } \\
\text { Value }\end{array}$ \\
\hline Pretest & 4.16 & 4 & 0.841 & & & \\
\hline Post & 6.12 & 6 & 1.189 & 49 & $13.46^{*}$ & 0.14 \\
\hline
\end{tabular}

* Significant at 0.05 level of significance

The descripted in table 1 show that the post-test knowledge scores of mean(6.12),median (6),SD (1.189) was higher than the pre-test mean (4.16),median (4) and $\mathrm{SD}$ ( 0.84 which was found to be statistically significant as evident from ' $t$ ' value of 13.46 for df49 at 0.05 level of significance. Thisshows that the obtained mean difference between the pretest and the posttest knowledge score was a 
true difference and not by chance. This indicates that the knowledge score of the posttest was significantly higher than the pretest. Which found that posttest knowledge of sample mothers were increased than pretest.

Table -2:_Mean, Median, SD, ' $t$ ' Value and P Value of pretest and posttest practice scores of sample mothers regarding kangaroo mother care.

$\mathrm{N}=50$

\begin{tabular}{|l|l|l|l|l|l|l|}
\hline Group & Mean & Med & SD & df & $\begin{array}{l}\text { T } \\
\text { Value }\end{array}$ & $\begin{array}{l}\text { P } \\
\text { Value }\end{array}$ \\
\hline Pretest & 4.32 & 4 & 0.998 & 49 & $23.01^{*}$ & 0.17 \\
\hline Post & 8.22 & 8 & 0.840 & & & \\
\hline
\end{tabular}

* Significant at 0.05 level of significance

Data shows in table 10 found that:

The post-test practice score of mean(8.22),median (8),SD (0.998) was higher than the pre-test mean (4.32),median (4) and SD ( 0.840) which was found to be statistically significant as evident from ' $t$ ' value of 23.01 for df49 at 0.05 level of significance. Thisshows that the obtained mean difference between the pretest and the posttest practice score was a true differenceand not by chance. This indicates that the practice score of the posttest was significantly higher than the pretest.

Ethical consideration: The research problem and objectives where approved by the research committee. Informed consent was obtained from the postnatal mothers in IMS and SUM Hospital. Explanation was given regarding the purpose of the study and confidentiality was ensured. Due permission from authorities has been sought and obtained

\section{CONCLUSION}

The conclusion was drawn after concluding the study. The study show that there was significant gain in knowledge and practice of KMC by postnatal mothers after the procedure done. Which found that posttest knowledge and practice of KMC of sample mothers were increased than pretest. The finding conclude that demonstration of $\mathrm{KMC}$ by the researcher was found to be helpful in enhancing knowledge and also the mothers implemented into practice with more satisfaction

\section{REFERENCES:}

1. Nyqvist $\mathrm{KH}$, Anderson GC, Bergman N, Cattaneo A, Charpak N, Davanzo R, Ewald U, Ibe O, Ludington-Hoe S, Mendoza S, Pallás-Allonso C. Towards universal kangaroo mother care: recommendations and report from the first European conference and seventh international workshop on kangaroo mother care. ActaPaediatrica. 2010 Jun 1;99(6):820-6.

2. Tessier R, Cristo M, Velez S, Girón M, de Calume ZF, Ruiz-Paláez JG, Charpak Y, Charpak N. Kangaroo mother care and the bonding hypothesis. Pediatrics. 1998 Aug 1;102(2):e17-.

3. Conde-Agudelo A, Díaz-Rossello JL. Kangaroo mother care to reduce morbidity and mortality in low birthweight infants. The Cochrane Library. 2016 Jan 1.

4. World Health Organization. Reproductive Health. Kangaroo mother care: a practical guide. World Health Organization; 2003 Apr 17.

5. Suman Rao PN, Udani R, Nanavati R. Kangaroo mother care for low birth weight infants: a randomized controlled trial. Indian pediatrics. 2008;45(1):17.

6. Charpak N, Figueroa Z. Kangaroo mother care programme practical rules. Bogota, Columbia: Kangaroo Foundation; 2001.

7. Brahmapurkar KP, Brahmapurkar VK, Zodpey SP. Under-Five Mortality Rate Reduction-a Challenge and Opportunity for Madhya Pradesh, India. Community Med. 2016;7(5):442-8.

8. Dodd VL. Implications of kangaroo care for growth and development in preterm infants. J ObstetGynecol Neonatal Nurs 2005; 34: 218-232.

9. Singh M. Temperature regulation. In: Care of the newborn. Singh M. 5th edition. New Delhi: Sagar Publications; 2000. p. 190-197. 